$\xi=-1$

\title{
Effect of Pressure on Expanded Polystyrene (EPS) Dry Mix Mortar Block
}

\author{
Adrina Rosseira $^{1 *}$, Syamsul Anua Mohd Dahari ${ }^{2}$, Kartini Kamaruddin ${ }^{3}$, Mazni Mat Zain ${ }^{4}$, Bazli Faliq Puaad ${ }^{5}$ \\ ${ }^{1}$ Faculty Of Civil Engineering, University of Technology Mara (Uitm) Pasir Gudang, Johor, Malaysia \\ *Corresponding Author E-Mail: Adrina9587@Johor.Uitm.Edu.My
}

\begin{abstract}
Nowadays, there is more demand than supply on the uses of material in the construction. Thus, the need to use alternative materials should be widely used and practiced among the construction and development to pro-longed the material for future generation supply. The objective of this study is to investigate the effect of different pressure exerted between $700 \mathrm{kPa}, 900 \mathrm{kPa}$ and $1100 \mathrm{kPa}$ to the replacement of Expanded Polystyrene (EPS) at $20 \%, 25 \%, 30 \%, 35 \%$ and $40 \%$ of sand replacement in achieving target strength of 5 $\mathrm{N} / \mathrm{mm}^{2}$ to $7 \mathrm{~N} / \mathrm{mm}^{2}$ of EPS dry mix mortar block. The tests were conducted at 7 and 28 days of curing with various replacements of EPS in the dry mix Besides, the study is also to identify the density of EPS Dry Mix Mortar Block due to pressure exerted (700 kPa, $900 \mathrm{kPa}$ and $1100 \mathrm{kPa}$ ) as a lightweight block. From the result that obtained, it was found that the most suitable pressure to be exerted is $700 \mathrm{kPa}$ since it was the less required pressure needed to achieve the target strength of 5-7 N/mm² at $20 \%$ of EPS replacement which is 5.74 $\mathrm{N} / \mathrm{mm}^{2}$. Besides, it was shown that the increase of pressure exerted to the EPS dry mix mortar block also will increased its density thus resulted in higher compressive strength.
\end{abstract}

\section{Introduction}

Normally, construction of building is made from concrete as main components. Concrete is a mixture of materials like sand, gravel, and small rocks combined with any type of cement and water. The mixture is then allowed to dry and harden. Basically, concrete is the stone-like structure formed after cement and other materials are mixed together. However, beside widely used all over the world for building construction, concrete also has some disadvantages. Concrete is very heavy, rigid, and its thermal and acoustical qualities are not very high (Mindess and Young, 1981). Therefore, due to innovation in modern building design, a mortar application was later introduced to be used as the replacement for wall and bricks. A mortar is a cement, fine sand and water that mix together to form lightweight concrete.

Dry mix mortar main ingredient consists of cement, sand and additive. Dry mix mortar blocks are lightweight, strong and can be produce for mass production in term of large panel of block. Expanded Polystyrene (EPS) is waste material that is suitable to be incorporated in the mortar mix to form dry mortar. EPS possess suitable properties such as low density, thermal insulation, hydrophobicity and chemical resistance when exposed to acids and alkalis. Besides, EPS is granulated into small particles that can be considered as non-absorbent and lightweight polymeric aggregate (Ferrandiz-Mas and García-Alcocel, 2013). Thus, in this study, EPS has been used to replace the sand proportion in the dry mix mortar due to extensive use and consumption of sand for mortar and concrete application in construction industries can lead to the reduction in amount of sand on the earth.

\section{Literature Review}

There are many efforts been carried out by researchers to utilize waste and reuse as replacement to the materials in mortar application such as cement and sand. For examples, there are many waste materials that been incorporated in producing construction materials such as plastic (Neville, 2002), rice husk and paper sludge ash (Ferrándiz-Mas and García-Alcocel, 2013) and many more. According to Noguchi et al. (1998), there were three (3) alternative ways on how to manage the EPS waste. First, the EPS waste can be managed by recycling method in which the volume of EPS is deducted either by friction, solvent or heating. Secondly, by chemical recycling of EPS waste by retreating process of the biological characteristic of polystyrene to be reutilize as the chemical resources. Besides, EPS waste that had been contaminated can be used for energy production by thermal recycling through combustion method. However, all of these options had contributed to the presence of contaminants and reduce the quality of recycle EPS.

In daily use, EPS been recycled and used for fish boxes, packaging for electrical consumer goods and for insulations panels for building (Ferraris et al., 2000) While in construction industries, The Plastic Portal (2014) reported that the major usage of EPS as for building panels and other construction parts. Kathirvale et al. (2004) stated that the major usage of EPS is for insulation foam for walls, roof and floor insulation and also as sound proof elements in bridge, road construction, retaining walls and also base- 
ment. There were not many studies that have been done in term of pressure applied to the dry mix mortar especially focusing on its effect to the replacement of material and compressive strength of the mortar itself. However, there is a study conducted on effect of pressure after casting on high strength fibre reinforced mortar but this study only focuses on the effects on the flexural response of high strength fibre reinforced mortar and together with its toughness by using Universal Testing Machine. According to Short and Kinniburgh (1978), the application of short term (about 15 minutes) pressure of up to $1,300 \mathrm{psi}(9 \mathrm{MPa})$ to a freshly cast fibre reinforced mortar leads to a slight increase in the proportional limit and elastic modulus of the resulting composite. However, it may also lead to a decrease in its modulus of rupture and its toughness.

\section{Methods and Material}

The materials used in this study were: Ordinary Portland cement conforming to BS 12:1978, grading test by sieve analysis showed the mining sand with complying to BS 933-1:2012 with fineness modulus of $0.15 \mathrm{~mm}$. The density of cement and sand obtained that has been tested using gas pycnometer method was 3,101 $\mathrm{kg} / \mathrm{m} 3$ and $2,654 \mathrm{~kg} / \mathrm{m} 3$ respectively. While density of EPS powder tested by using bulk density test was $18 \mathrm{~kg} / \mathrm{m} 3$.

\subsection{Preparation of Specimens}

In this study, the basic mix proportion of dry mix mortar with EPS powder replacement was cement: sand with ratio of $1: 2.5$. The content of EPS applied in this study were with the replacement proportion of $20 \%, 25 \%, 30 \%, 35 \%$ and $40 \%$ to the sand volume. The EPS powder ratio was calculated as the ratio of the mass of the total dry mix content to the mass of the sand in the in the dry mix content.

Mixing of cement, sand and water to form control mix. Then, addition of EPS as a sand replacement at $20 \%, 25 \%, 30 \%, 35 \%$, and $40 \%$. The ratio of the cement in the mix remains the same in all mix while the ratio of the sand will be differing as the increasing of EPS powder ratio replacement in the mix. The procedure was repeated until $40 \%$ of EPS powder replacement. Mix were cast into cubes $100 \times 100 \times 100 \mathrm{~mm}$ and placed under hydraulic press machine for designated pressure of $700 \mathrm{kPa}, 900 \mathrm{kPa}$ and $1,100 \mathrm{kPa}$. The specimens were demoulded approximately $24 \mathrm{~h}$ after casting and then subjected to 7 and 28 days of curing.

\subsection{Compressive Strength Test}

The specimens were tested for compressive strength according to BS EN 12390-3:2000. The pace or loading rates of compressive strength test was $3 \mathrm{kN} / \mathrm{s}$.

\subsection{Section Headings}

No more than 3 levels of headings should be used. Other headings must be in 9pt font. Only the first word in a heading must be capitalized and other word should be in small case.

\subsubsection{Figure Captions}

Figures must be numbered using Arabic numerals. Figure captions must be in 8 pt Regular font. Captions of a single line (e.g. Figure 2) must be centered whereas multi-line captions must be justified (e.g. Figure 1). Captions with figure numbers must be placed after their associated figures, as shown in Figure 1.

\section{Results and Findings}

There were two findings that has been obtained in this study which are compressive strength and the relationship between pressures exerted and density of EPS Dry Mix Mortar Block.

\subsection{Compressive Strength at 7 and 28 Days of Curing}

The compressive strength test result for control (EPS $0 \%$ ), dry mix mortar with EPS powder replacement $(20 \%, 25 \%, 30 \%, 35$ $\%$ and $40 \%$ ) at 7 and 28 days were shown as shown in Figure 1. The trend of data is similar for 7 and 28 days. Therefore, the graph plotted only for compressive strength at 28 days as theory of concrete design stated that the concrete will gained its strength rapidly until 28 days after casting. From Figure 2, it can be seen that the increased in amount of EPS replacement resulted in increased of compressive strength. For example, the compressive strength of control mix is the lowest compared to mix design with EPS replacement of $20 \%, 25 \%, 30 \%, 35 \%$ and $40 \%$. The target strength of 5-7 N/mm $\mathrm{mm}^{2}$ for mix with applied pressure of $700 \mathrm{kPa}$ and $900 \mathrm{kPa}$ achieved at mix with minimum EPS replacement of $20 \%$ which the result is $5.74 \mathrm{~N} / \mathrm{mm}^{2}$ and $5.947 \mathrm{~N} / \mathrm{mm}^{2}$ respectively. However, for mix applied with $1,100 \mathrm{kPa}$, the target strength already achieved at control mix which is $7.53 \mathrm{~N} / \mathrm{mm}^{2}$ and mix with $20 \%$ of EPS replacement surpass target strength which is $12.83 \mathrm{~N} / \mathrm{mm}$. This result indicates that the pressure applied to the mix also play a greater role in affecting the compressive strength of the mix.

Figure 4 shows the compressive strength for design mix with applied pressure of $700 \mathrm{kPa}$ and $900 \mathrm{kPa}$ at 7 and 28 days of curing. The exclusion of mix with applied pressure of $1100 \mathrm{kPa}$ is because the target strength already achieved at control mix which is 5.27 $\mathrm{N} / \mathrm{mm}^{2}$ at 7 days and $7.53 \mathrm{~N} / \mathrm{mm}^{2}$ at 28 days. In term of relation between pressure applied to the mix and percentage of EPS replacement, the more pressure applied resulted in higher compressive strength obtained for those mix with higher percentage of EPS replacement. For example, the compressive strength for mix with $20 \%$ of EPS replacement with applied pressure of $900 \mathrm{kPa}$ was $5.947 \mathrm{~N} / \mathrm{mm}^{2}$ and were higher than mix with $20 \%$ of EPS replacement with applied pressure of $700 \mathrm{kPa}$ valued at 5.74 for both 7 and 28 days. This may due to the composition of the mix in the mould being well compacted when pressed with higher pressure resulted in improve bonding between cement, sand and EPS thus increased in compressive strength. From the result that obtained, it was found that the most suitable pressure to be exerted is $700 \mathrm{kPa}$ since it was the less required pressure needed to achieve the target strength of $5-7 \mathrm{~N} / \mathrm{mm}^{2}$ at $20 \%$ of EPS replacement which is $5.74 \mathrm{~N} / \mathrm{mm}^{2}$.

\begin{tabular}{|c|c|c|c|c|c|c|}
\hline \multirow{2}{*}{$\begin{array}{l}\text { EPS } \\
\text { Replacement } \\
(\%)\end{array}$} & \multicolumn{5}{|c|}{ Compressive Strength (N/mm²) } \\
\cline { 2 - 7 } & \multicolumn{2}{|c|}{$700 \mathrm{kPa}$} & \multicolumn{2}{|c|}{$900 \mathrm{kPa}$} & \multicolumn{2}{c|}{$1100 \mathrm{kPa}$} \\
\cline { 2 - 7 } & $\mathbf{7 d}$ & $\mathbf{2 8 d}$ & $\mathbf{7 d}$ & $\mathbf{2 8 d}$ & $\mathbf{7 d}$ & $\mathbf{2 8 d}$ \\
\hline EPS $_{0 \%}$ & 2.695 & 4.36 & 4.212 & 4.545 & 5.27 & 7.53 \\
\hline $\mathrm{EPS}_{20 \%}$ & 4.165 & 5.74 & 4.725 & 5.947 & 7.44 & 12.83 \\
\hline $\mathrm{EPS}_{25 \%}$ & 5.91 & 8.075 & 6.194 & 9.338 & 12.68 & 17.15 \\
\hline $\mathrm{EPS}_{30 \%}$ & 7.15 & 9.23 & 7.519 & 10.775 & 21.09 & 28.75 \\
\hline $\mathrm{EPS}_{35 \%}$ & 7.435 & 9.515 & 7.835 & 11.580 & 19.00 & 25.74 \\
\hline $\mathrm{EPS}_{40 \%}$ & 8.77 & 10.34 & 9.480 & 12.770 & 13.57 & 21.09 \\
\hline
\end{tabular}

Figure 1: Compressive Strength and EPS Replacement Percentage with different pressures exerted at 7 and 28 days of curing 


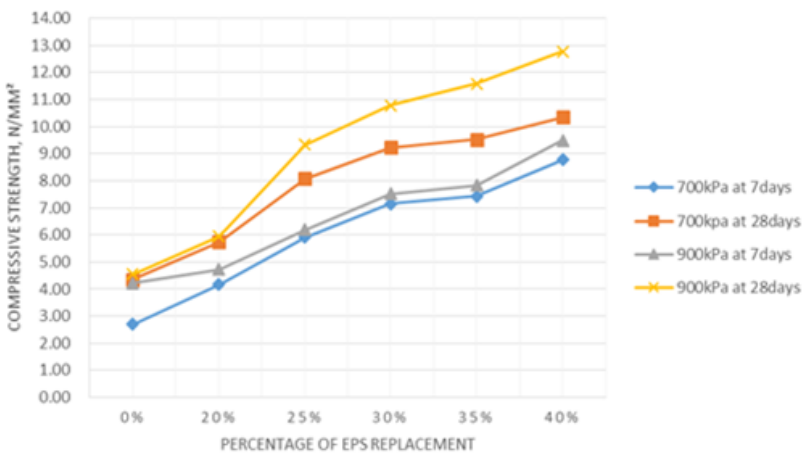

Figure 2: The graph of compressive strength of dry mix mortar tested at 28 days

\subsection{Relationship between Pressures Exerted and Density of EPS Dry Mix Mortar Block}

Figure 3 showed the pressures, EPS replacement percentage, density and compressive strength of dry mix mortar taken at 28 days of curing. Figure 5 shows the relationship between density and the pressure exerted for each design mix at 28 days. The blue line indicates mix design with pressure of $700 \mathrm{kPa}$, while orange and grey indicate for mix design with pressure of $900 \mathrm{kPa}$ and 1100 $\mathrm{kPa}$ respectively. It was shown that the increase of pressure exerted to the EPS dry mix mortar will increased the density. As the pressure applied on a material increases, the material density increases as the atoms or molecules of the material are pushed more closely together. However, EPS dry mix mortar with exerted pressure of $700 \mathrm{kPa}$ is the lowest density and suitable since the purpose is to produce lightweight block because the higher density will result in higher weight thus will not contribute in forming a lightweight EPS dry mix mortar block.

\begin{tabular}{|c|c|c|c|c|c|c|}
\hline $\begin{array}{l}\text { EPS } \\
\text { Replacement } \\
(\%)\end{array}$ & \multicolumn{2}{|c|}{$700 \mathrm{kPa}$} & \multicolumn{2}{|c|}{$900 \mathrm{kPa}$} & \multicolumn{2}{c|}{$1100 \mathrm{k}$} \\
\cline { 2 - 7 } & $\begin{array}{l}\text { Density } \\
\left(\mathrm{kg} / \mathrm{m}^{3}\right)\end{array}$ & $\begin{array}{l}\text { Comp. } \\
\text { Strength }\end{array}$ & $\begin{array}{l}\text { Density } \\
\left(\mathrm{kg} / \mathrm{m}^{3}\right)\end{array}$ & $\begin{array}{l}\text { Comp. } \\
\text { Strength }\end{array}$ & $\begin{array}{l}\text { Density } \\
\left(\mathrm{kg} / \mathrm{m}^{3}\right)\end{array}$ & $\begin{array}{l}\text { Comp. } \\
\text { Strength }\end{array}$ \\
\hline EPS $_{0 \%}$ & 1570 & 4.36 & 1656 & 4.545 & 1650 & 7.53 \\
\hline $\mathrm{EPS}_{20 \%}$ & 1595 & 5.74 & 1624 & 5.947 & 1910 & 12.83 \\
\hline $\mathrm{EPS}_{25 \%}$ & 1675 & 8.075 & 1703 & 9.338 & 1950 & 17.15 \\
\hline EPS $_{30 \%}$ & 1694 & 9.23 & 1792 & 10.775 & 2070 & 28.75 \\
\hline EPS $_{35 \%}$ & 1728 & 9.515 & 1839 & 11.580 & 1940 & 25.74 \\
\hline EPS $_{40 \%}$ & 1784 & 10.34 & 1846 & 12.770 & 1990 & 21.09 \\
\hline
\end{tabular}

Figure 3: The pressures, EPS replacement percentage, density and compressive strength of dry mix mortar taken at 28 days of curing.

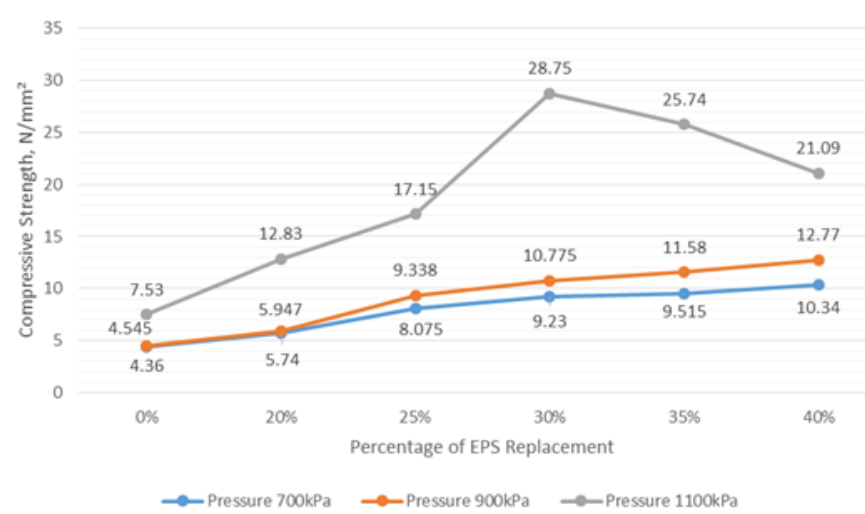

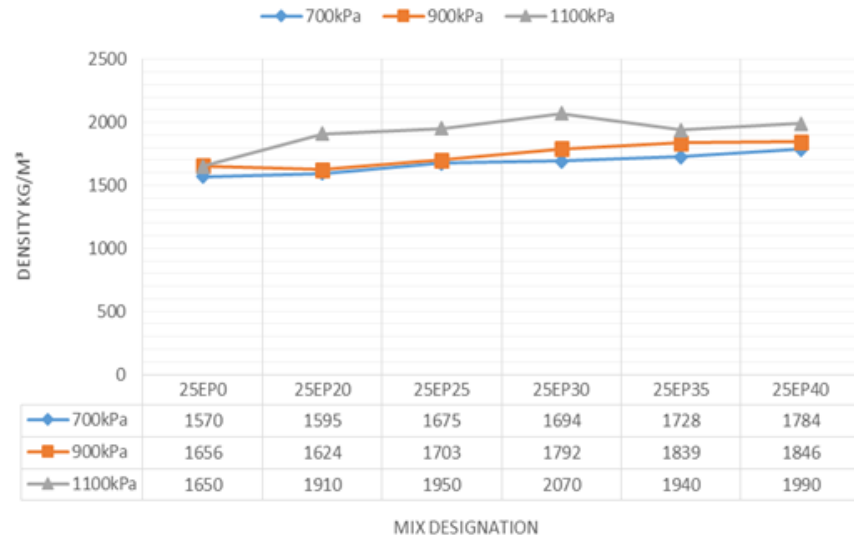

Figure 5: Relationship between pressures exerted and density and EPS Dry Mix Mortar Block

\section{Conclusion}

From the results of the test that have been conducted, it can be concluded that: The increase amount of EPS replacement will increase the compressive strength of EPS dry mix mortar. Target strength of 5-7 N/mm² for mix with applied pressure of $700 \mathrm{kPa}$ and $900 \mathrm{kPa}$ achieved at mix with minimum EPS replacement of $20 \%$ which the result is $5.74 \mathrm{~N} / \mathrm{mm}^{2}$ and $5.947 \mathrm{~N} / \mathrm{mm}^{2}$ respectively. The suitable pressure exerted to achieve target strength of $5-7 \mathrm{~N} / \mathrm{mm}^{2}$ is $700 \mathrm{kPa}$ since it was the less required pressure needed compared to $900 \mathrm{kPa}$ and $1,100 \mathrm{kPa}$. Therefore, less pressure required, save time and cost when it comes to production of mortar block. The increase of pressure exerted to the EPS dry mix mortar will increased the density. Therefore, EPS dry mix mortar with exerted pressure of $700 \mathrm{kPa}$ is the lowest density and most lightweight thus suitable for lightweight mortar block.

\section{References}

[1] Ferrándiz-Mas, V., García-Alcocel, E., 2013, Durability of expanded polystyrene mortars. Construction and Building Materials, 46, 175-182.

[2] Ferraris, C. F., Brower, L., Ozyildirim, C., Daczko, J., 2000, Workability of self-compacting concrete. Symp. Proc. of

PCI/FHWA/FIB Int. Symposium on 'High Performance Concrete: The Economical Solution for Durable Bridges and Transportation Structures," Orlando (FL), 25-27.

[3] Kathirvale, S., Yunus, M. N. M., Sopian, K., Samsuddin, A. H., 2004, Energy potential from municipal solid waste in Malaysia, Renewable Energy, 29, 559-567.

[4] Mindess, S., Young, J., 1981, Concrete, Prentice Hall, New Jersey, USA.

[5] Neville, A. M., 2002. Properties of Concrete, Longman, London, UK.

[6] Noguchi, T., Miyashita, M., Inagaki, Y., Watanabe, H., 1998, A new recycling system for expanded polystyrene using a natural solvent. Part 1. A new recycling technique, Packaging Technology and Science, 11, 19-27.

[7] Short, A., Kinniburgh, W., 1978, Lightweight Concrete, Appl. Sci. Publ., 3-rd ed, London, UK.

Figure 4: The graph of compressive strength tested at 28 days 